\title{
Effects of Nanoclay on Tensile and Flexural Properties of Pineapple Leaf Fibre Reinforced Phenolic Composite
}

\author{
M. Asim, M. T. Paridah, M. Jawaid, M. Nasir, R. Siakeng
}

\begin{abstract}
Phenolic based PALF/nanoclay hybrid composites was prepared by adding Montmorillonite (MMT) as filler at different loading (1\%, $2 \%$ and 3\%) by using hot press technique. Obtained results indicated that adding MMT in PALF/phenolic composites considerably improves the tensile and flexural strength and modulus. Tensile properties showed that the tensile strength increased after adding MMT though tensile modulus decreased. Flexural strength and modulus were enhanced after adding MMT up to $2 \%$, further addition of MMT declined the properties. $2 \%$ MMT showed better tensile and flexural properties. $3 \%$ MMT/PALF hybrid composite showed no further improvement in tensile properties after $2 \%$ MMT, however the flexural properties were reduced. 3\% MMT did not improved much maybe agglomeration accrued. PALF/nanoclay/phenolic hybrid composites revealed good mechanical properties that encourage to use for structural purposes.
\end{abstract}

Index Terms: Phenolic resin, PALF, Nano clay, Tensile properties, Flexural properties.

\section{INTRODUCTION}

From the last few decades, fabrication of lignocellulosic fibres reinforced composites have been increased due to its suitability to replace the synthetic fibres reinforced composites $[1,2]$. The lignocellulosic fibres based composites revealed some specific characteristics such as biodegradability, low density, cheap manufacturing cost, better specific strength and modulus, easily machinery process, insulation properties, sound absorption properties, low energy consumption and ecofriendly [3]. Natural fibre reinforced composites can degrade naturally and it can also degrade forcibly at the end of their life cycle by burial process as land filling or can be retain the calorific values in furnace [4].

Though, these natural fibres composites have several demerits over the synthetic composites such as least water resistant, weaker interfacial bonding causes lower mechanical

Revised Manuscript Received on July 05, 2019.

M. Asim, Institute of Tropical Forestry and Forest Products (INTROP), Universiti Putra Malaysia, Serdang, Selangor, Malaysia. Corresponding author.Email: asimkhan@upm.edu.my

M.T. Paridah, Institute of Tropical Forestry and Forest Products (INTROP), Universiti Putra Malaysia, Serdang, Selangor, Malaysia. Corresponding author.Email: parida@upm.edu.my

M. Jawaid, Institute of Tropical Forestry and Forest Products (INTROP), Universiti Putra Malaysia, Serdang, Selangor, Malaysia

M Nasir, Forest Products Utilization, college of forestry, Banda University of Agriculture and Technology, Banda, India

R Siakeng, Graduate School of Engineering (TGGS), King Mongkut's University of Technology North Bangkok, Bangsue, Bangkok, Thailand properties, lower thermal stability due to hemicellulose and cellulose [5]. These disadvantages can be minimize by modification of fibre's surfaces or by addition of some additive/nano fillers such as nanocellulose, silica, nanotubes, nanoclay etc. [6].

In filler, constituent of aluminosilicate layers surface substituted with metal cations in Montmorillonite (MMT) is stacked in $10 \mu \mathrm{m}$-sized multilayer stacks. The morphology of the MMT particles are plate-shaped and size around $1 \mu \mathrm{m}$ with high aspect ratio [7, 8]. MMT is highly reactive filler which provide higher cation exchange capacity and the structure; octahedral charge nearly $50 \%$ help in reactivity due to isomorphous substitution of $\mathrm{Mg}$ for $\mathrm{Al}$ ) [9, 10]. The nanocomposites are fabricated by using nanoclay such as MMT, OMMT as filler in polymers [11]. The specific active charges and high aspect ratio of MMT revealed various possible applications, the nanocomposites have efficiency of load tolerance from the matrix which help to improve mechanical properties and stiffness to the nanocomposites [12]. F. Uddin [13] studied the fillers lamellar nanoclay and OMMT is in the range of $5-10 \mathrm{wt} . \%$ in nanocomposites, he assumed that high aspect ratio of filler were more than 1000 , nearly $750 \mathrm{~m}^{2} / \mathrm{g}$ was estimated surface higher modulus values (176 GPa).

Many researchers studied nano filler/natural fibres hybrid composite such as nanoclay used as filler in bagasse reinforced polypropylene nanocomposites [14], graphene nano platelets used in kenaf fibers reinforced polypropylene nanocomposites [15], nanoclay as filler in bagasse flour reinforced recycled polyethylene [16], nanoclay used as filler in bagasse flour reinforced high density polyethylene [17], NCC extracted from oil palm shells used as filler in coconut fiber/kenaf fiber (woven mat) reinforce polyester hybrid composite [18]. Faruk and Matuana [19] studied wood flour/HDPE composites and investigated mechanical properties and found appropriate ratio of coupling agent content and nanoclay in composites improved significantly. The nano clay filler nanocomposites showed drastic improvement in mechanical strength, modulus, thermal barrier properties, fire retardancy, resistant to weather degradation, heat resistance, water resistant and compared to the conventional composites. Most of the reported works based on nanocomposites revealed better mechanical, thermal electrical and physical properties.

Published By: 
Present work deals with effect of MMT on mechanical properties such as tensile and flexural properties of PALF reinforced phenolic composites. After the addition of MMT, these advancements of hybrid composites materials are assumed to enhance the tensile and flexural properties of pineapple leaf fibre reinforced phenolic composites. The developed hybrid composites will extend the area of research such as thermal, physical and flammability properties.

\section{MATERIALS AND METHOD}

\section{A. Materials}

The polymer is thermoset, phenol formaldehyde (PF), Novolac (Grade PH-4055) bought from Chemovate Girinagar, Banglore, India. The natural fibre (pineapple leaf fibre) were harvested and extracted in India. Basic characteristics of natural fibre and matrix have been depicted in Table 1. It is montmorillonite (MMT) nanoclay modified with 15-35 wt\% octadecylamine and 0.5-5 wt $\%$ aminopropytriethoxysilane. The density of the nanoclay ranged from $200-500 \mathrm{~kg} / \mathrm{m}^{3}$ and was supplied in powder form with dull white color.

Table 1. Characteristics of phenolic resin and pineapple leaf fibres (PALF)

\begin{tabular}{|c|c|c|c|}
\hline Properties & $\begin{array}{l}\text { Phenolic } \\
\text { resin }\end{array}$ & Properties & PALF \\
\hline Physical state & Powder & $\begin{array}{l}\text { Density } \\
\left(\mathrm{g} / \mathrm{cm}^{3}\right)\end{array}$ & 1.53 \\
\hline Colour & $\begin{array}{l}\text { Pale yellow } \\
\text { colour }\end{array}$ & $\begin{array}{l}\text { Cellulose } \\
\text { content }(\%)\end{array}$ & 70.51 \\
\hline Odour & $\begin{array}{c}\text { Slide odour } \\
\text { of phenol }\end{array}$ & $\begin{array}{l}\text { Hemicellulose } \\
\text { content }(\%)\end{array}$ & 14.21 \\
\hline $\mathrm{pH}$ & $8-8.5$ & $\begin{array}{l}\text { Lignin } \\
\text { content }(\%)\end{array}$ & 2.93 \\
\hline Density(g/cm3) & 1.28 & $\begin{array}{l}\text { Fibre } \\
\text { diameter }(\mu \mathrm{m})\end{array}$ & 78.8 \\
\hline Melting point & $70-73^{\circ} \mathrm{C}$ & $\begin{array}{l}\text { Tensile strength } \\
\text { (MPa) }\end{array}$ & 290.61 \\
\hline Curing time & \begin{tabular}{|l|}
$45 \mathrm{sec}$ to \\
95 \\
minutes \\
\end{tabular} & $\begin{array}{l}\text { Tensile } \\
\text { modulus } \\
(\mathrm{MPa})\end{array}$ & 5831.59 \\
\hline Screen test & \begin{tabular}{|l}
$300-320$ \\
mesh with < \\
$2 \%$ retention \\
\end{tabular} & & \\
\hline Free phenol & $<1 \%$ strictly & & \\
\hline
\end{tabular}

\section{B. Fabrication of Composite}

PALF fibre used as reinforced material in PF composites. PALF was used as short fibre, was ground into $0.8-1 \mathrm{~mm}$ by using grinding machine and moisture content was maintained 6-8\%. The composites were fabricated by hand layup technique. The mould used was stainless metal plate having dimensions $15 \times 15 \times 3 \mathrm{~mm}$. the mould was press in hot press for $8 \mathrm{~min}$ and removed for cool down to room temperature. The samples were prepared according to ASTM standard. The formulation of composite fabrication is tabulated in Table 2.
Table 2. Fabrication of PALF/MMT hybrid composites.

\begin{tabular}{cccc}
\hline $\begin{array}{c}\text { Fibre's ratio in hybrid } \\
\text { composites }\end{array}$ & $\begin{array}{c}\text { PALF } \\
\text { (wt\%) }\end{array}$ & $\begin{array}{c}\text { MMT } \\
\text { (wt } \%)\end{array}$ & $\begin{array}{c}\text { PF } \\
\text { (wt } \%)\end{array}$ \\
\hline 1\%MMT/PALF/PF & 49 & 1 & 50 \\
2\%MMT/PALF/PF & 48 & 2 & 50 \\
3\%MMT/PALF/PF & 47 & 3 & 50 \\
\hline
\end{tabular}

\section{CHARACTERIZATIONS}

\section{A. Tensile Test}

The tensile strength and modulus of PALF/MMT filled phenolic hybrid composites were investigated according to ASTM standards D3039 [20] by using $5 \mathrm{kN}$ Blue hill INSTRON Universal Testing Machine. All samples were conditioned for $48 \mathrm{hrs}$ at $22^{\circ} \mathrm{C}$ and $50 \%$ humidity. All the samples were cut in size of $120 \times 20 \times 3 \mathrm{~mm}$. Average of all tensile strength and modulus were taken and evaluated

\section{B. Flexural Test}

Flexural tests of MMT filled in PALF/PF composites were investigated according to ASTM D790 standard [21] by by using $5 \mathrm{kN}$ Bluehill INSTRON Universal Testing Machine. All the samples were cut in size of $120 \times 20 \times 3 \mathrm{~mm}$. Average of all tensile strength and modulus were taken and evaluated.

\section{RESULTS AND DISCUSSION}

\section{A. Tensile Properties}

The mechanical properties such as tensile strength and modulus of MMT filled PALF/PF composites were studies on various percentage of MMT. From Figure 1, it can be seen the tensile strength is increasing with increasing the percentage of MMT, 2\% MMT composites showed drastic enhancement in tensile strength in compare to the $3 \%$ MMT composites. Though tensile modulus dropped. Further increasing the MMT ratio in hybrid composite did not give much impact on tensile strength and tensile modulus was also same as $2 \%$ MMT hybrid composites tabulated in Table 3. After addition of MMT in composites, PLAF/phenolic composites improved the mechanical properties which showed the interfacial bonding of fibre-matrix has been improved.

Table 3. Tensile and flexural properties of PALF/MMT hybrid composites

\begin{tabular}{lcccc}
\hline \multirow{2}{*}{$\begin{array}{c}\text { Hybrid } \\
\text { composites }\end{array}$} & \multicolumn{2}{c}{ Tensile } & \multicolumn{2}{c}{ Flexural } \\
\cline { 2 - 5 } & $\begin{array}{c}\text { Strength } \\
(\mathrm{MPa})\end{array}$ & $\begin{array}{c}\text { Modulus } \\
(\mathrm{GPa})\end{array}$ & $\begin{array}{c}\text { Strength } \\
(\mathrm{MPa})\end{array}$ & $\begin{array}{c}\text { Modulus } \\
(\mathrm{GPa})\end{array}$ \\
\hline 1\% MMT & 27.57 & 6.84 & 50.5513 & 4.22 \\
$2 \% \mathrm{MMT}$ & 34.07 & 5.77 & 70.6637 & 4.69 \\
$3 \% \mathrm{MMT}$ & 35.23 & 5.84 & 63.7906 & 4.52 \\
\hline
\end{tabular}

Previous research based on nanoclay filled polymer composites enhance the mechanical properties. It may be due to optimal limitations of physical properties

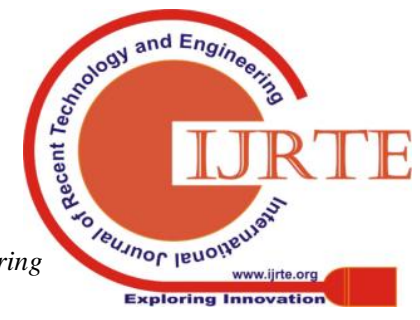


nano-materials and matrix. It is also assumed that the nanoclay behave as thermal retardant and it behave differently to the chemical reactions cause obstacle in completing the curing process of composite. So it might possible in those samples have high nanoclay content, the matrix of that samples might not be fully cured [22].
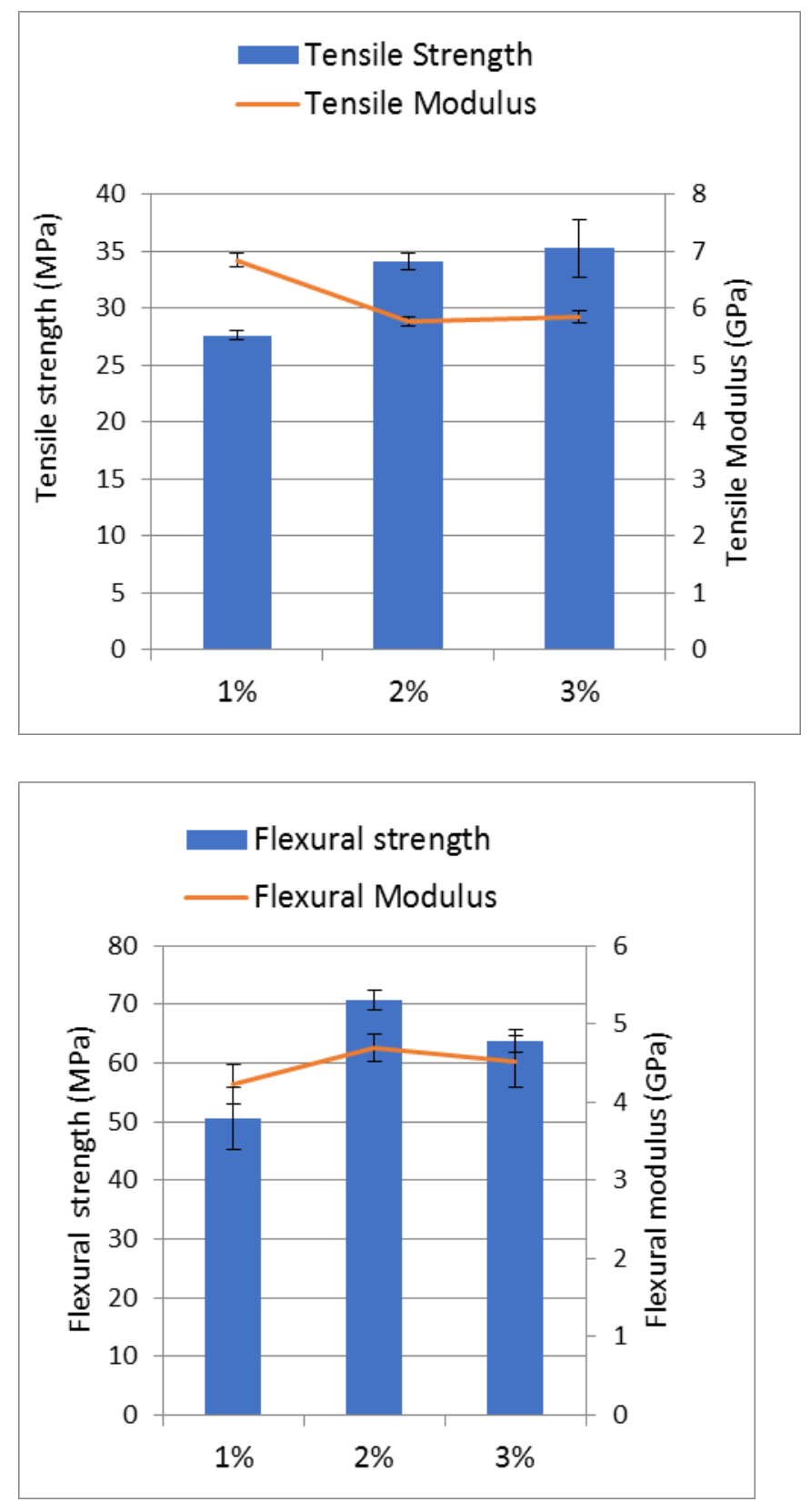

Fig. 1: Tensile properties of PALF/MMT hybrid composites

The chances of agglomeration in higher content of nanoparticles in composites are higher causes poor mechanical strength $[23,24]$. Another study showed effects of different amounts of CNFs used in epoxy composites revealed improved tensile strength due to nano materials. The fabricated nanocomposites revealed more stiffness and tougher due to stiff and hard nature of CNFs[25]. Another research based on CNFs and bleached Eucalyptus Kraft Pulp based nanocomposites improved the mechancial properties [26]. The Relatively higher tensile strength value of
PALF/MMT Nanocomposites showed that dispersion of MMT in composites is homogeneous and interaction with PALF and PF is appropriate. Though, increasing the amount of MMT showed agglomeration within composite and voids causes initial cracks and lower tensile strength and modulus as compared to the $2 \%$ MMT hybrid composites.

\section{B. Flexural Properties}

Flexural test reveals the combine properties of tensile and compressive strength. Flexural test is a combine mechanism of some different testings such as tension, compression, shearing, etc. [27]. The flexural strength is directly depend to the interlaminar shear strength, however the flexural modulus measures the composites resistant to bending deformation. In figure 2, flexural properties of PALF/PF nanocomposites revealed relativily same trends of improvement with tensile properties, even though flexural strenght and modulus revealed declined trend after optimum ratio of MMT. Optimum amount of MMT is required due to higher rigidity, higher interface area and stiffness. The MMT fillers directly involve in improvement in flexural strength and modulus as the stress gets efficiently transferred via the interface.

Figure 2. Flexural properties of PALF/MMT hybrid composites Figure 2. Flexural properties of PALF/MMT hybrid composites

The MMT content 2\% revealed drastic improvement in flexural strength and modulus, it may be due to the better interfacial bonding characteristics with matrix. Further increasing the MMT content reduced the flexural strength and modulus shown in table 2 . The reason of better flexural modulus may be due to the exfoliation and good dispersion of MMT. Good dispersion of MMT restricts the mobility of polymer chains under loading as well as help to make good interfacial adhesion among the MMT, fibre and the PF matrix [23]. Similar study based on polyester hybrid composites revealed improved elastic modulus with nanoclay but higher percentage of nanoclay further reduced the flexural modulus. This declined elastic modulus at higher clay content attributed to the presence of unexfoliated aggregates [24]. Which showed the sign of MMT aggregation and early cracks in hybrid composites as compare to the 2\% MMT hybrid composites.

\section{CONCLUSION}

- $1 \%$ MMT hybrid composites showed highly brittle and less tensile and flexural properties in comparison to rest hybrid composites. $1 \%$ MMT showed insufficient amount to spread throughout the composite, so it is unable to transfer the mechanical strength.

- $2 \%$ MMT nanocomposites revealed better flexural strength and modulus however tensile strength and modulus are nearly equal to the $3 \%$ MMT hybrid composites.

- $3 \%$ MMT nanocomposites depicted highest tensile

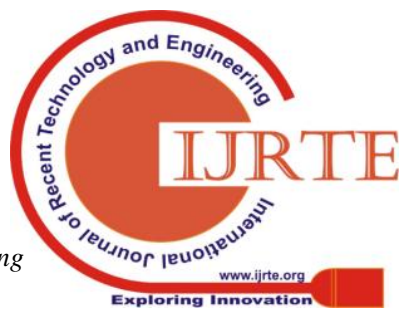


strength and lower modulus which shows less rigid character of hybrid composites. Flexural properties showed highest at 2\% MMT hybrid composites after increasing MMT content the properties dropped, which revealed the optimum percentage of MMT in composites.

\section{REFERENCES}

1. R. Yahaya, S. Sapuan, M. Jawaid, Z. Leman, and E. Zainudin, "Effect of layering sequence and chemical treatment on the mechanical properties of woven kenaf-aramid hybrid laminated composites," Materials \& Design, vol. 67, (2015), pp. 173-179.

2. M. Asim, M. Jawaid, K. Abdan, and M. Ishak, "Effect of pineapple leaf fibre and kenaf fibre treatment on mechanical performance of phenolic hybrid composites," Fibers and Polymers, vol. 18, (2017), pp. 940-947.

3. M. Asim, M. Jawaid, M. Nasir, and N. Saba, "Effect of fiber loadings and treatment on dynamic mechanical, thermal and flammability properties of pineapple leaf fiber and kenaf phenolic composites," Journal of Renewable Materials, vol. 6, no. 4, (2017) pp. 383-393.

4. H.-y. Cheung, M.-p. Ho, K.-t. Lau, F. Cardona, and D. Hui, "Natural fibre-reinforced composites for bioengineering and environmental engineering applications," Composites Part B: Engineering, vol. 40 (2009), pp. 655-663.

5. M. Asim, M. Paridah, N. Saba, M. Jawaid, O. Y. Alothman, M. Nasir, et al., "Thermal, physical properties and flammability of silane treated kenaf/pineapple leaf fibres phenolic hybrid composites," Composite Structures, vol. 202, (2018), pp. 1330-1338.

6. N. Saba, M. Paridah, and M. Jawaid, "Mechanical properties of kenaf fibre reinforced polymer composite: A review," Construction and Building materials, vol. 76, (2015), pp. 87-96.

7. T. Nakato and N. Miyamoto, "Liquid crystalline behavior and related properties of colloidal systems of inorganic oxide nanosheets," Materials, vol. 2, (2009), pp. 1734-1761.

8. N. Saba, M. Jawaid, and M. Asim, "Recent advances in nanoclay/natural fibers hybrid composites," in Nanoclay reinforced polymer composites, ed: Springer, (2016), pp. 1-28.

9. M.-1. Chan, K.-t. Lau, T.-t. Wong, M.-p. Ho, and D. Hui, "Mechanism of reinforcement in a nanoclay/polymer composite," Composites Part B: Engineering, vol. 42, (2011), pp. 1708-1712.

10. M.-1. Chan, K.-t. Lau, T. Wong, and F. Cardona, "Interfacial bonding characteristic of nanoclay/polymer composites," Applied Surface Science, vol. 258, (2011), pp. 860-864.

11. H. Assaedi, F. Shaikh, and I. M. Low, "Effect of nano-clay on mechanical and thermal properties of geopolymer," Journal of Asian Ceramic Societies, vol. 4, (2016), pp. 19-28

12. B. De, K. Gupta, M. Mandal, and N. Karak, "Biocide immobilized OMMT-carbon dot reduced $\mathrm{Cu} 2 \mathrm{O}$ nanohybrid/hyperbranched epoxy nanocomposites: Mechanical, thermal, antimicrobial and optical properties," Materials Science and Engineering: C, vol. 56, (2015), pp. 74-83.

13. F. Uddin, "Studies in finishing effects of clay mineral in polymers and synthetic fibers," Advances in Materials Science and Engineering, vol. 2013, (2013).

14. A. Nourbakhsh and A. Ashori, "Influence of nanoclay and coupling agent on the physical and mechanical properties of polypropylene/bagasse nanocomposite," Journal of applied polymer science, vol. 112, (2009), pp. 1386-1390.

15. C. I. Idumah and A. Hassan, "Characterization and preparation of conductive exfoliated graphene nanoplatelets kenaf fibre hybrid polypropylene composites," Synthetic Metals, vol. 212, (2016), pp. 91-104.

16. A. H. Hemmasi, I. Ghasemi, B. Bazyar, and A. Samariha, "Studying the effect of size of bagasse and nanoclay particles on mechanical properties and morphology of bagasse flour/recycled polyethylene composites," BioResources, vol. 8, (2013), pp. 3791-3801.

17. A. Samariha, A. H. Hemmasi, I. Ghasemi, B. Bazyar, and M. Nemati, "Effect of nanoclay contents on properties, of bagasse flour/reprocessed high density polyethylene/nanoclay composites," Maderas. Ciencia y tecnología, vol. 17, (2015), pp. 637-646.

18. E. Rosamah, M. S. Hossain, H. Abdul Khalil, W. Wan Nadirah, R. Dungani, A. Nur Amiranajwa, et al., "Properties enhancement using oil palm shell nanoparticles of fibers reinforced polyester hybrid composites," Advanced Composite Materials, vol. 26, (2017), pp. 259-272.
19. O. Faruk and L. M. Matuana, "Nanoclay reinforced HDPE as a matrix for wood-plastic composites," Composites Science and Technology, vol. 68, (2008), pp. 2073-2077.

20. M. Asim, M. Jawaid, K. Abdan, and M. Ishak, "The effect of silane treated fibre loading on mechanical properties of pineapple leaf/kenaf fibre filler phenolic composites," Journal of Polymers and the Environment, vol. 26, (2018), pp. 1520-1527.

21. A. C. Milanese, M. O. H. Cioffi, and H. J. C. Voorwald, "Thermal and mechanical behaviour of sisal/phenolic composites," Composites Part B: Engineering, vol. 43, (2012), pp. 2843-2850.

22. C.-K. Lam, H.-y. Cheung, K.-t. Lau, L.-m. Zhou, M.-w. Ho, and D. Hui, "Cluster size effect in hardness of nanoclay/epoxy composites," Composites Part B: Engineering, vol. 36, (2015), pp. 263-269.

23. R. Velmurugan and T. Mohan, "Epoxy-clay nanocomposites and hybrids: synthesis and characterization," Journal of Reinforced Plastics and Composites, vol. 28, (2009), pp. 17-37.

24. P. K. Kushwaha and R. Kumar, "Reinforcing effect of nanoclay in bamboo-reinforced thermosetting resin composites," Polymer-Plastics Technology and Engineering, vol. 50, (2011), pp. 127-135.

25. N. Saba, F. Mohammad, M. Pervaiz, M. Jawaid, O. Alothman, and M. Sain, "Mechanical, morphological and structural properties of cellulose nanofibers reinforced epoxy composites," International journal of biological macromolecules, vol. 97, (2017), pp 190-200.

26. B. Barari, T. K. Ellingham, I. I. Ghamhia, K. M. Pillai, R. El-Hajjar, L.-S. Turng, et al., "Mechanical characterization of scalable cellulose nano-fiber based composites made using liquid composite molding process," Composites Part B: Engineering, vol. 84, (2016), pp. 277-284.

27. M. Asim, M. Jawaid, K. Abdan, M. Ishak, and O. Alothman, "Effect of Hybridization on the Mechanical Properties of Pineapple Leaf Fiber/Kenaf Phenolic Hybrid Composites," Journal of Renewable Materials, vol. 6, (2018), pp. 38-46.

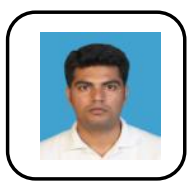

M. Asim is Post-Doctoral fellow in Institute of Tropical Forestry and Forest Products (INTROP), University Putra Malaysia. His area of expertise is polymer composites. He has published 35 articles in international journals, book chapters and proceedings.

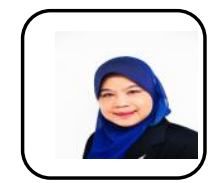

Paridah Md Tahir is a professor in Institute of Tropical Forestry and Forest Products (INTROP), University Putra Malaysia. Her area of expertise is Wood Chemistry. She has published more than 250 articles in numerous journals, co-authored 6 books and more than 100 chapters in book, proceedings, technical and consultation reports.

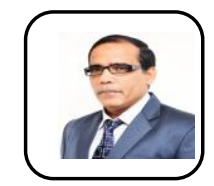

M. Jawaid is currently working as Fellow Researcher at Institute of Tropical Forestry and Forest Products (INTROP), Universiti Putra Malaysia. His area of expertise is polymer science. he has published 8 books, 25 book chapters, and more than 250 International journal papers.

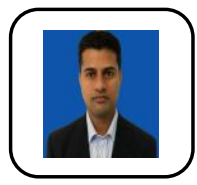

M. Nasir is assistant professor in college of forestry, Banda University of Agriculture and Technology, Banda, India. His area of expertise is wood science and technology. He has published 40 articles in international journals, book chapters and proceedings.

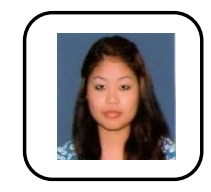

R. Siakeng is completed doctorate degree in Bio-composites Technology from Institute of Tropical Forestry and Forest Products (INTROP), Universiti Putra Malaysia. She has published 10 articles in international journals, book chapters and proceedings. 